\title{
Evaluating Equity and Coverage in Mass Drug Administration for Soil-Transmitted Helminth Infections among School-Age Children in the Hard-to-Reach Setting of Southern Ethiopia
}

\author{
Mekuria Asnakew Asfaw (D) \\ Chernet Hailu (iD) ${ }^{2}$ \\ Tariku J Beyene 3 \\ 'Collaborative Research and Training \\ Centre for NTDs, Arba Minch University, \\ Arba Minch, Ethiopia; ${ }^{2}$ Jimma University, \\ Faculty of Public Health, Department of \\ Epidemiology, Jimma, Ethiopia; ${ }^{3}$ Center \\ for Surgical Outcomes Research, \\ Research Institute at Nationwide \\ Children's Hospital, Columbus, $\mathrm{OH}$, \\ 430I5, USA
}

Background: Soil-transmitted helminth (STH) infections are prevalent in most developing countries, including Ethiopia, with school-age children (SAC) at high risk of infection. In Ethiopia, despite substantial progress being made on mass drug administration (MDA) coverage for STH infections, its implementation is facing challenges in hard-to-reach areas. This study thus aimed at assessing equity and coverage in MDA and identifying factors associated with drug coverage for STH infections among SAC in the hard-to-reach setting of southern Ethiopia.

Methods: A community-based cross-sectional survey was conducted in the North Ari district, South Omo Zone in July 2019. Sample size was estimated following WHO drugcoverage evaluation guidelines. Factors associated with drug uptake for STH infections were identified using multivariate logistic regression.

Results: Of 956 SAC participating in this study, the overall MDA coverage for STH was found to be $27.5 \%$ (95\% CI $24.7 \%-30.5 \%)$. The odds of having taken drugs were highest among school-enrolled children and in those who knew the purpose of MDA: about about double their counterparts. In contrast, the odds of drug uptake were lower by $69 \%$ among those who had got informed only when the drugs delivered and by $92 \%$ among those who needed to travel $>30$ minutes to reach drug-distribution points than their counterparts.

Conclusion: Achieving effective and equitable MDA coverage is facing serious challenges in the hard-to-reach setting of southern Ethiopia. The very low $(27.5 \%)$ and inequitable MDA coverage found in this study are associated with school nonenrollment, inaccessibility, and lack of information, awareness, and mobilization. Social mobilization should be scaled up to inform and create awareness in the community ahead of MDA. Further, school-based deworming in settings with low school enrollment needs a modified strategy to reach those in need of drugs.

Keywords: equity, mass drug administration, soil-transmitted helminths, North Ari, hard-toreach setting

\section{Introduction}

Soil-transmitted helminths (STHs) are a group of parasitic intestinal worms, ie, roundworm (Ascaris lumbricoides), whipworm (Trichuris trichiura), and hookworms (Ancylostoma duodenale and Necator americanus) that are prevalent in places where the soil is warm and humid and sanitation is lacking. ${ }^{1-3}$ They are among the common neglected tropical diseases (NTDs), which are a diverse group
Correspondence: Mekuria Asnakew Asfaw

Tel +25I-9I-202-95I7

Email maksambaramr23@gmail.com 
of diseases that affect impoverished, marginalized, and remote communities. $^{1,2}$ Risk factors of STH infections include poor hygiene, lack of sanitation, and low socioeconomic status. $^{4,5}$

It is estimated that $>2$ billion people around the world are affected by $\mathrm{STHs}^{2,3}$ and $>550$ million school-age children (SAC) worldwide at risk of STH infections. ${ }^{6}$ STHs are widespread in most developing countries, including Ethiopia, with high prevalence among SAC. ${ }^{3,4,7}$ STHrelated morbidity associated with moderate or heavy infection intensity results in anemia, stunted growth, loss of education, and cognitive problems in children. ${ }^{3,8}$

According to the World Health Organization (WHO), at least $75 \%$ of SAC should be covered by mass drug administration (MDA) in an endemic area. ${ }^{3}$ In 2017, it was reported that $>500$ million SAC $(69 \%$ of total SAC in need) received preventive chemotherapy (PC) through MDA for STHs globally, with $73 \%$ of implementation units reaching the recommended coverage. More than 596 million SAC in 101 countries were estimated to be in need of PC for STH infections in 2017. ${ }^{9}$ STHs are targeted to be eliminated as a public-health problem by 2030 , defined as a $<2 \%$ proportion of STH infections of moderate and heavy infection intensity, as stated in the new revised WHO's NTD roadmap of 2021-2030. ${ }^{10}$ To control and eliminate STH infections, PC using annual or biannual single-dose albendazole $(400 \mathrm{mg}$ ) or mebendazole $(500 \mathrm{mg})$ has been provided as a public-health intervention for all SAC living in areas where the baseline prevalence of any STH is $20 \%$ or higher in children to reduce the worm burden of STHs. ${ }^{2,3,7}$ Controlling NTDs through $\mathrm{PC}$ in at-risk populations provides a cost-effective way of improving health equity in endemic countries. ${ }^{11}$ Furthermore, for sustained solutions, it is advocated that the STH-control program is complemented with measures that ensure access to improve sanitation, health, and hygiene behaviors, such as hand-washing and the use of footwear through health education. ${ }^{3}$ In 2016, the global NTD program passed the half-billion mark, reaching 531 million children in need of deworming. This accounted for $63 \%$ of global needs, an increase from $58.5 \%$ in 2015. Of the 103 STH-endemic countries, 77 reported conducting deworming of SAC. ${ }^{1}$ However, reaching children who are not attending schools through school-based control programs remains a challenge in remote settings to achieve the required treatment coverage. $^{2}$
The NTD program is an entry point to universal health coverage, ${ }^{1}$ and the WHO set a global target to end NTDs by 2030 , as mentioned in target 3.3 of the Sustainable Development Goals, ${ }^{12}$ leaving no one behind from accessing basic health services by $2030 .^{13}$

In Ethiopia, $>81$ million people are living in STHendemic areas, of which 25.3 million are SAC. About 1 million SAC got dewormed for STH infections in 2007 in Ethiopia, and in 2013 and 2014, 11.6 million and 7.8 million SAC received treatment, respectively. Following the launch of the countrywide school-based deworming program in November 2015, nearly 13 million SAC received drugs against STHs. ${ }^{14}$ Since 2015, MDA for STHs among SAC using a school-based deworming platform has been implemented in Ethiopia and remarkable achievements observed regarding MDA coverage; however, segments of the population are still left behind from accessing PC, especially in the hard-toreach setting of southern Ethiopia. ${ }^{15}$

The WHO recommends that all SAC (both enrolled and nonenrolled) be treated through school-based deworming. Implementation of deworming using the school platform is facing challenges, due to a significant proportion of SAC in many developing countries not attending school. Although good results have been obtained by encouraging SAC to bring their nonenrolled siblings and friends to school on a treatment day, ${ }^{16}$ this has not brought substantial change insouthern Ethiopia. For example, in South Omo Zone, data obtained from records at the the zonal health department have shown persistently low $<50 \%$ - administrative drug coverage for STHs has been reported for $>3$ years.

To achieve the STH-program goals, effective and equitable coverage is vital. It is thus important to conduct periodic epidemiological surveys to assess equity and coverage in MDA and identify factors associated with drug uptake. The STH program within the health system calculates and reports administrative mass-treatment coverage by adding reports received from drug distributors. However, these reports are often prone to error, and thus evidence is lacking on equity and coverage in MDA and factors associated with drug uptake in southern Ethiopia. Therefore, this study aimed at determining MDA coverage, assessing equity of MDA with respect to sex, age, place of residence, educational level, and school attendance, and identifying factors associated with drug consumption for STH infections in the North Ari district of South Omo Zone, a hard-to-reach area. 


\section{Methods}

\section{Study Design and Period}

A community-based cross-sectional study was conducted in July 2019 to assess the coverage, equity, and factors associated with drug uptake for STHs.

\section{Study Setting}

This study was conducted in the North Ari district of South Omo Zone, about $940 \mathrm{~km}$ southwest of Addis Ababa, the capital Ethiopia. The population in the zone is estimated to be 577,673 (288,638 male and 289,035 female), and that of North Ari was projected to be 18,495 by the central statistical authority in $2007 .{ }^{17}$ There are transportation problems in the entire district, and it is very far from regional and zone towns. The absence of roads for four-wheel vehicles and motorcycles makes for hard-to-reach data-collection sites. As such, the study area is defined as hard-to-reach setting. STH infections are a common and prevalent NTD in the district, and have been affecting the community, mainly SAC. ${ }^{14}$

\section{Study Populations}

The study population was selected SAC who lived in the study area during the MDA campaign that was happened head of the survey. Only children aged 5-14 years (according to SAC categorization) were included. Since there is no consistent definition of SAC in the existing literature, in this study all children aged 5-14 years were considered SAC, as per a WHO guideline. $^{16,17}$ Participants were excluded if they were nonresidents (had come to visit their relatives), were seriously ill, or parents were unable to deliver their information.

\section{Sample-Size Determination and Sampling Strategy}

As this study adopted coverage-evaluation survey methodology, sample size was estimated using multistage cluster sampling following WHO guidelines to evaluate coverage and equity of MDA. ${ }^{18}$ The Survey Sample Builder tool was used, which generates an equal probability proportional to each village of the survey population by assuming expected coverage of $71 \%{ }^{19}$ by considering desired precision of $5 \%$, $\alpha=5 \%$, design effect of 3 , and $10 \%$ nonresponse rate. Figure 1 shows the sampling strategy. In total, 30 segments were systematically selected from the subunits (villages) by taking probability proportional to estimated population size into consideration, and from each selected segment at least 16 randomly selected households were included. From each selected household, SAC who were resident and available during the MDA campaign participated in the study. To include eligible household members that were absent at the time of the interview, the survey team made an attempt to revisit the household or a primary caretaker was asked to answer on their behalf.

\section{Study Variables}

The dependent variable was STH-drug uptake and independent variables sex, age, place of residence, school attendance, educational level, information-, social mobilization-, and awareness-related characteristics, place of drug distribution, availability of drug distributors while taking the drugs, participants informed about MDA ahead of time, ways participants were informed, and time taken to reach drug-distribution points.

\section{Data Collection}

Data were collected using a pretested questionnaire by experienced and trained health professionals who were members of the community, but not involved in the MDA campaign through home visits. Data collectors used a sample of albendazole or mebendazole tables to show and confirm the type of drug the children received so that recall bias was minimized. Children or their primary caregivers were asked for information regarding each variable. If there were no SAC in the selected household or if the entire household was absent and not expected to return later in the day, the survey team moved to the next
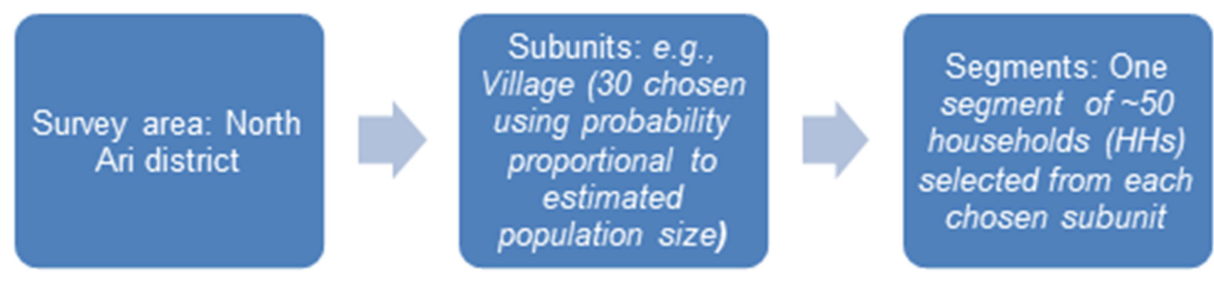

Participants:

School-aged

children in the

survey population

in the selected HHs

Figure I Sampling strategy. 
household. Moreover, the survey team attempted to revisit the household if children were absent, but expected to return later in the same day. Data from very young children $(<7$ years old) were collected from their parents or caregivers.

\section{Data Analysis}

Data were coded, entered into EpiData 4.4.2, and exported to SPSS 25 for analysis. Factors associated with STH-drug uptake were assessed using multivariate logistic regression. Bivariate analysis, interaction effects, multicollinearity, and assumption of \#x1D712; ${ }^{2}$ were checked before fitting to the multivariate model. Goodness of model fitness was checked for the full model using the HosmerLemeshow test at $P>0.05$.

Equity in MDA coverage was assessed by disaggregating data by sex, age, place of residence, school enrollment, and educationlevel, and presented in tables. Differences in coverage of MDA between or among groups was checked using $\# \mathrm{x} 1 \mathrm{D} 712{ }^{2}$ tests $(P<0.05)$.

In this study, drug coverage was defined as the proportion of individuals who had taken a drug, calculated as such:

Total number of interviewed individuals

that swallowed the target drug

Total number of interviewed individuals $* 100 \%$

Equity is defined as preventable, unfair, or remediable differences among groups of people, whether those groups are defined socially, economically, demographically, or geographically. ${ }^{11}$ In this study, it was defined as all individuals in need of PC regardless of sex, age, place of residence, education level, school enrollment, place of education, and other differences.

\section{Ethics}

Ethics approval was granted by the Institutional Research Ethics Review Board of Arba Minch University, College of Medicine and Health Sciences, Ethiopia (CMHS12032750/111). The study was conducted in accordance with the Declaration of Helsinki. All participants were informed about the purpose of the study. Oral and written informed consent was obtained from parents or legal guardians, with informed assent from the children before data collection, and participation was totally voluntary. The study team had a meeting with the district health office head and village chiefs, where the purpose of the survey was explained and verbal permission obtained to perform the survey.

\section{Results}

\section{Sociodemographic Characteristics}

In total, 956 participants were involved in this study. Of these, the proportion of boys was higher than girls $(55.9 \%$ versus $44.1 \%$ ), almost two-thirds (645) were aged 5-10 years of age group, a majority (96.4\%) were living in rural area, three-quarters (718) were attending school, most $(92.2 \%)$, most at the primary level, and $>95 \%$ at government schools (Table 1). Table 1 summarizes the sociodemographic characteristics of participants.

\section{MDA-Implementation Strategies Information, Social Mobilization, and Awareness Regarding MDA}

Ahead of the actual MDA campaign, it was recommended that the district health office in collaboration with healthextension workers perform health education in schools and communities to create awareness and improve knowledge, attitudes, and practice related to MDA and STH prevention and control. However, in this study, of the total study participants (956), more than half (52.8\%) did not know anything about MDA, only $50.4 \%$ had heard about the MDA campaign. Of those informed, a majority (68.7\%) had heard 1 day prior, more than half $(53.5 \%)$ had been informed on the location and time of MDA, and $47.2 \%$ knew about the purpose of taking the drugs (Table 2).

\section{MDA Coverage and Self-Reported Reasons for Not Being Offered Drugs}

Overall MDA coverage for STHs was $27.5 \%$ (95\% CI $24.7 \%-30.5 \%$ ), much lower than the WHO's recommended coverage (at least $75 \%$ ). Self-reported cases of drugs was not

Table I Sociodemographic characteristics of participants $(n=956)$

\begin{tabular}{|l|l|l|l|}
\hline & Category & $\mathbf{n}$ & $\%$ \\
\hline Sex & Male & 534 & 55.9 \\
& Female & 422 & 44.1 \\
\hline Age (years) & $5-10$ & 645 & 67.5 \\
& $11-14$ & 311 & 32.5 \\
\hline School enrollment & Yes & 688 & 72 \\
& No & 268 & 28 \\
\hline Education (n=688) & Primary & 634 & 92.2 \\
& Secondary & 54 & 7.8 \\
\hline Place of education $(\mathrm{n}=688)$ & Private & 13 & 1.9 \\
& Government & 675 & 98.1 \\
\hline
\end{tabular}


Table 2 Information, social mobilization, and awareness regarding MDA

\begin{tabular}{|c|c|c|c|}
\hline & Category & $n$ & $\%$ \\
\hline $\begin{array}{l}\text { Heard of MDA ahead } \\
\text { of time }\end{array}$ & $\begin{array}{l}\text { Yes } \\
\text { No }\end{array}$ & $\begin{array}{l}482 \\
474\end{array}$ & $\begin{array}{l}50.4 \\
49.6\end{array}$ \\
\hline $\begin{array}{l}\text { Before how many days } \\
\text { informed about MDA } \\
(n=482)\end{array}$ & $\begin{array}{l}\text { One } \\
\text { Two } \\
\text { Three }\end{array}$ & $\begin{array}{l}331 \\
128 \\
23\end{array}$ & $\begin{array}{l}68.7 \\
26.5 \\
4.8\end{array}$ \\
\hline $\begin{array}{l}\text { How informed on } \\
\text { MDA }(n=482)\end{array}$ & $\begin{array}{l}\text { Teacher } \\
\text { Community meeting } \\
\text { Health professional } \\
\text { Crier }\end{array}$ & $\begin{array}{l}118 \\
7 \\
228 \\
129\end{array}$ & $\begin{array}{l}24.5 \\
1.5 \\
47.5 \\
26.8\end{array}$ \\
\hline $\begin{array}{l}\text { Informed about } \\
\text { location and time of } \\
\text { MDA }(n=482)\end{array}$ & $\begin{array}{l}\text { Location } \\
\text { Time } \\
\text { Location and time }\end{array}$ & $\begin{array}{l}192 \\
32 \\
258\end{array}$ & $\begin{array}{l}39.8 \\
6.6 \\
53.5\end{array}$ \\
\hline $\begin{array}{l}\text { Do you know about } \\
\text { MDA? }\end{array}$ & $\begin{array}{l}\text { Yes } \\
\text { No }\end{array}$ & $\begin{array}{l}451 \\
505\end{array}$ & $\begin{array}{l}47.2 \\
52.8\end{array}$ \\
\hline $\begin{array}{l}\text { What do you know } \\
\text { about MDA }(n=45 I) \text { ? }\end{array}$ & $\begin{array}{l}\text { About the disease } \\
\text { given for } \\
\text { Color and amount } \\
\text { of drugs }\end{array}$ & $\begin{array}{l}280 \\
|7|\end{array}$ & $\begin{array}{l}62.1 \\
37.9\end{array}$ \\
\hline
\end{tabular}

being offered/given came to $98.7 \%$ (684 of 693 ), and the main self-reported reason for this was not being informed $(42.8 \%, 293$ of 684$)$ and long distance to drug-distribution points $(26 \%, 178$ of 684 ; Table 3$)$. With regard to place of distribution, we found health posts $(43 \%)$ and schools $(42.6 \%)$ were the main distribution points, while $41.8 \%$ of participants needed to for $>30$ minutes to reach the distribution points. In most (97.1\%) drug-distribution points, community drug distributors (CDDs) were available (Table 3).

\section{MDA Coverage for STHs}

The survey showed that MDA coverage for STHs was $27.5 \%$ (95\% CI $24.7 \%-30.5 \%)$.

\section{Equity in MDA Coverage for STHs among SAC}

This study showed inequities in MDA coverage based on coverage data disaggregated by gender, age, place of residence, school enrollment, and education level. There was a a significant difference in drug uptake based on schoolenrollment status (\#x1D712 $;^{2}=52.01, P=0$, Table 4).

\section{Factors Associated with STH-Drug Uptake}

On univariate analysis, variables identified with $P \leq 0.25$ for STH-drug uptake were place of residence, school
Table 3 MDA coverage, implementation, and self-reported reasons for not being offered drugs $(n=956)$

\begin{tabular}{|c|c|c|c|}
\hline & Category & $\mathbf{n}$ & $\%$ \\
\hline \multirow[t]{2}{*}{ Offered drugs } & Yes & 272 & 28.5 \\
\hline & No & 684 & 71.5 \\
\hline \multirow{2}{*}{ Took drugs } & Yes & 263 & 27.5 \\
\hline & No & 693 & 72.5 \\
\hline \multirow{4}{*}{$\begin{array}{l}\text { MDA-distribution point } \\
(\mathrm{n}=272)\end{array}$} & Home & 12 & 4.4 \\
\hline & School & 116 & 42.6 \\
\hline & Health post & 117 & 43.0 \\
\hline & Central point & 27 & 9.9 \\
\hline \multirow{3}{*}{$\begin{array}{l}\text { Time taken to reach drug- } \\
\text { distribution points }\end{array}$} & $>60$ minutes & 234 & 24.5 \\
\hline & $30-60$ minutes & 165 & 17.3 \\
\hline & $<30$ minutes & 557 & 58.3 \\
\hline \multirow{2}{*}{$\begin{array}{l}\text { CDDs available while } \\
\text { drugs were offered }(n=272)\end{array}$} & Yes & 264 & 97.1 \\
\hline & No & 8 & 2.9 \\
\hline \multirow{3}{*}{$\begin{array}{l}\text { Perceived reasons for not } \\
\text { taking drugs }(n=693)\end{array}$} & Fear of side effect & 7 & 1.0 \\
\hline & Do not like test & 2 & 0.3 \\
\hline & Not offered/given & 684 & 98.7 \\
\hline \multirow{5}{*}{$\begin{array}{l}\text { Perceived reasons for not } \\
\text { being offered drugs }(n=684)\end{array}$} & Not informed & 293 & 42.8 \\
\hline & Felt healthy & 107 & 15.6 \\
\hline & Long distance to & 178 & 26.0 \\
\hline & MDA site & & \\
\hline & Do not attend school & 106 & 15.5 \\
\hline
\end{tabular}

attendance, informed of MDA ahead of time, knowledge about MDA, what known about MDA, how informed on MDA, informed about location and time of distribution, CDDs available while drugs were offered, and time taken to reach distribution sites. To improve the likelihood of the remaining variables being included in the multivariate model, we used a cutoff of $P \leq 0.25$ to select candidate variables.

Following univariate analysis, all variables with $P \leq 0.25$ that met the $\# \times 1 \mathrm{D} 712 ;^{2}$ assumptions were entered into a multivariate logistic regression model using the backward-stepwise method. The variable "availability of CDDs while drugs were offered" was not entered into the model, since it did not meet the \#x1D712; ${ }^{2}$ assumptions (one cell [25\%] with expected count $<5$ ). After adjustment for confounding variables, the multivariate model identified the following variables as potential factors associated with STH-drug uptake. The odds ofSTH-drug uptake were highest among those SAC who were enrolled in school (AOR 2.29, 95\% CI 1.13-4.61) and among those who knew the purpose of the drug (AOR 2.27, 95\% CI 1.443.59). On the other hand, the odds of STH-drug uptake were lower by $69 \%$ among SAC who were informed only 
Table 4 Equity in MDA coverage $(n=956)$

\begin{tabular}{|c|c|c|c|c|c|c|}
\hline & \multirow[t]{2}{*}{ Category } & \multicolumn{2}{|c|}{ Drug uptake } & \multirow{2}{*}{$\begin{array}{l}\text { Mean difference in } \\
\text { drug coverage }\end{array}$} & \multirow[t]{2}{*}{$\# x|D 7| 2 ;^{2}$} & \multirow[t]{2}{*}{$P$} \\
\hline & & Yes & No & & & \\
\hline Sex & $\begin{array}{l}\text { Male } \\
\text { Female }\end{array}$ & $\begin{array}{l}\text { I5I (28.3\%) } \\
112(26.5 \%)\end{array}$ & $\begin{array}{l}383(71.7 \%) \\
310(73.5 \%)\end{array}$ & $1.8 \%$ & 0.36 & 0.56 \\
\hline $\begin{array}{l}\text { Age } \\
\text { (years) }\end{array}$ & $\begin{array}{l}5-10 \\
11-14\end{array}$ & $\begin{array}{l}179(27.8 \%) \\
84(27 \%)\end{array}$ & $\begin{array}{l}466(72.2 \%) \\
227(73 \%)\end{array}$ & $0.8 \%$ & 0.06 & 0.81 \\
\hline $\begin{array}{l}\text { School } \\
\text { level }\end{array}$ & $\begin{array}{l}\text { Primary } \\
\text { Secondary }\end{array}$ & $\begin{array}{l}218(34.4 \%) \\
16(29.6 \%)\end{array}$ & $\begin{array}{l}416(65.6 \%) \\
38(70.4 \%)\end{array}$ & $4.8 \%$ & 0.50 & 0.48 \\
\hline $\begin{array}{l}\text { School } \\
\text { enrollment }\end{array}$ & $\begin{array}{l}\text { Yes } \\
\text { No }\end{array}$ & $\begin{array}{l}234(34 \%) \\
29(10.8 \%)\end{array}$ & $\begin{array}{l}454(66 \%) \\
239(89.2 \%)\end{array}$ & $23.2 \%$ & 52.01 & 0 \\
\hline $\begin{array}{l}\text { Place of } \\
\text { education }\end{array}$ & $\begin{array}{l}\text { Government } \\
\text { Private }\end{array}$ & $\begin{array}{l}187(29.5 \%) \\
\text { I (12.5\%) }\end{array}$ & $\begin{array}{l}447(70.5 \%) \\
7(87.5 \%)\end{array}$ & $17 \%$ & 1.10 & 0.29 \\
\hline
\end{tabular}

when the drug would be delivered compared to those who were informed of the location and time of MDA (AOR 0.31, 95\% CI 0.12-0.82). In addition, the STH-drug uptake was lower among SAC who needed to travel $>90$ minutes to reach drug-distribution points by $88 \%$ (AOR 0.22 , 95\% CI $0.14-0.35$ and 92\%, AOR 0.08, 95\% CI $0.04-0.17$, respectively) compared to the reference category (Table 5).

\section{Discussion}

Despite the significant progress that has been made in terms of reaching STH-affected communities through MDA, the findings of this study showed low and inequitable MDA coverage for STHs in SAC in the hard-toreach setting of southern Ethiopia. We identified school enrollment, accessibility, and information, awareness, and mobilization as associated factors with STH-drug uptake among SAC.

MDA coverage was found to be very low (27.5\%) compared to the target coverage set by the WHO (at least $75 \%)^{3}$ and also less than PC coverage estimated on a global level in 2017 (68.8\%). ${ }^{18}$ Likewise, it was much lower than the coverage estimated by a study done in ten districts of Ethiopia (71\%). ${ }^{19}$ However, coverage was in alignment with that in different countries using 2016 WHO PC data, where 31 countries achieved $<75 \%$ MDA coverage, including Ethiopia. On the other hand, 57 countries achieved $\geq 75 \%$ PC coverage ${ }^{18}$ Similarly, in 2017 , a WHO report noted that 36 countries met the target. ${ }^{9}$

We found very low MDA coverage (27.5\%) in this study, lower than the administration-reported coverage
$(34.5 \%)$. This may have been due to the fact that reported coverage is often subject to error. The finding collaborates with studies conducted in other parts of Ethiopia, ${ }^{19}$ in other countries, ${ }^{20}$ and in Bangladesh. ${ }^{21}$

In this study, slightly higher MDA coverage in boys was observed thangirls $(28.5 \%$ versus $26.5 \%)$. On the contrary, evidence from 16 countries indicated that female coverage was slightly higher than male coverage. ${ }^{22}$ The difference in this finding might be due a norm that may prevail in the study area that favors male individuals in terms of a higher chance of attending school and taking drugs than their female counterparts.

Evidence showed that exclusive school-based deworming was unable to reach children not attending school. ${ }^{21}$ In the present survey, treatment coverage in school-attending children was $34 \%$, significantly higher than coverage among nonenrolled children (10.8\%). Low school enrollment and a high dropout rate in the study area could be reasons for the low drug coverage in nonenrolled children. This is consistent with studies conducted in Ethiopia ${ }^{19}$ and Bangladesh. ${ }^{21}$ In addition, a finding of a previous coverage survey conducted in Ethiopia showed that only about half of nonenrolled children received drugs for STHs, whereas $>95 \%$ of school-attending children did. ${ }^{23}$

The difference in of MDA coverage for STHs among SAC living in urban areas was notable compared to children living in rural areas (58.2\% versus $26.4 \%$ ). The low rural coverage might be due to geographical inaccessibility related to the hard-to-reach setting of the study area where limited infrastructure exists, eg, lack of roads would make it difficult to reach all individuals in need of PC. 
Table 5 Univariate and multivariate analyses of factors associated with drug uptake

\begin{tabular}{|c|c|c|c|c|c|}
\hline & \multirow[t]{2}{*}{ Category } & \multicolumn{2}{|c|}{$\begin{array}{l}\text { STH-drug } \\
\text { uptake }\end{array}$} & \multirow[t]{2}{*}{$\begin{array}{l}\text { Univariate analysis, } \\
\text { COR }(95 \% \mathrm{CI})\end{array}$} & \multirow[t]{2}{*}{$\begin{array}{l}\text { Multivariate analysis, } \\
\text { AOR }(95 \% \mathrm{CI})\end{array}$} \\
\hline & & Yes & No & & \\
\hline Sex & $\begin{array}{l}\text { Male } \\
\text { Female }\end{array}$ & $\begin{array}{l}151 \\
112\end{array}$ & $\begin{array}{l}383 \\
310\end{array}$ & $\begin{array}{l}\text { I.09 }(0.82-1.45) \\
\text { Reference }\end{array}$ & - \\
\hline Age (years) & $\begin{array}{l}5-10 \\
11-14\end{array}$ & $\begin{array}{l}179 \\
84\end{array}$ & $\begin{array}{l}466 \\
227\end{array}$ & $\begin{array}{l}\text { I.04 (0.77-I.4I) } \\
\text { Reference }\end{array}$ & - \\
\hline Enrolled in school & $\begin{array}{l}\text { Yes } \\
\text { No }\end{array}$ & $\begin{array}{l}216 \\
47\end{array}$ & $\begin{array}{l}530 \\
163\end{array}$ & $\begin{array}{l}2.40(2.80-6.44)^{* *} \\
\text { Reference }\end{array}$ & $\begin{array}{l}2.29(1.13-4.61)^{*} \\
\text { Reference }\end{array}$ \\
\hline School level & $\begin{array}{l}\text { Primary } \\
\text { Secondary }\end{array}$ & $\begin{array}{l}218 \\
16\end{array}$ & $\begin{array}{l}416 \\
38\end{array}$ & $\begin{array}{l}\text { I.25 (0.68-2.28) } \\
\text { Reference }\end{array}$ & - \\
\hline Informed about MDA ahead of time & $\begin{array}{l}\text { Yes } \\
\text { No }\end{array}$ & $\begin{array}{l}228 \\
35\end{array}$ & $\begin{array}{l}254 \\
439\end{array}$ & $\begin{array}{l}\text { II.26 (7.64-16.59)** } \\
\text { Reference }\end{array}$ & - \\
\hline $\begin{array}{l}\text { How many days before did you get informed } \\
\text { about MDA? }(n=482)\end{array}$ & $\begin{array}{l}\text { One } \\
\text { Two } \\
\text { Three }\end{array}$ & $\begin{array}{l}150 \\
66 \\
12\end{array}$ & $\begin{array}{l}181 \\
62 \\
11\end{array}$ & $\begin{array}{l}\text { I.32 (0.56-3.07) } \\
\text { I.03 (0.42-2.49) } \\
\text { Reference }\end{array}$ & - \\
\hline Do you know about MDA? & $\begin{array}{l}\text { Yes } \\
\text { No }\end{array}$ & $\begin{array}{l}210 \\
53\end{array}$ & $\begin{array}{l}241 \\
452\end{array}$ & $\begin{array}{l}7.43(5.29-10.44)^{* *} \\
\text { Reference }\end{array}$ & \\
\hline What do you know about MDA? & $\begin{array}{l}\text { About the } \\
\text { disease given for } \\
\text { Color and drug }\end{array}$ & $\begin{array}{l}147 \\
63\end{array}$ & $\begin{array}{l}133 \\
108\end{array}$ & $\begin{array}{l}\text { I.89 (1.28-2.80)** } \\
\text { Reference }\end{array}$ & $\begin{array}{l}2.27(1.44-3.59)^{*} \\
\text { Reference }\end{array}$ \\
\hline How informed about MDA $(n=482)$ & $\begin{array}{l}\text { Teacher } \\
\text { Community } \\
\text { meeting } \\
\text { Health } \\
\text { professional } \\
\text { Town crier }\end{array}$ & $\begin{array}{l}73 \\
2 \\
93 \\
60\end{array}$ & $\begin{array}{l}45 \\
5 \\
135 \\
69\end{array}$ & $\begin{array}{l}0.54(0.32-0.89)^{* *} \\
2.17(0.41-11.62) \\
1.26(0.82-1.95) \\
\text { Reference }\end{array}$ & - \\
\hline $\begin{array}{l}\text { Informed about location and time of MDA } \\
(n=482)\end{array}$ & $\begin{array}{l}\text { Where } \\
\text { When } \\
\text { Where and when }\end{array}$ & $\begin{array}{l}78 \\
20 \\
130\end{array}$ & $\begin{array}{l}114 \\
12 \\
128\end{array}$ & $\begin{array}{l}\text { I.48 (I.02-2.16)** } \\
0.61(0.29-1.30)^{* *} \\
\text { Reference }\end{array}$ & $\begin{array}{l}\text { I.42 }(0.92-2.26) \\
0.31(0.12-0.82)^{*} \\
\text { Reference }\end{array}$ \\
\hline Time taken to reach distribution site & $\begin{array}{l}>60 \text { minutes } \\
30-60 \text { minutes } \\
<30 \text { minutes }\end{array}$ & $\begin{array}{l}143 \\
66 \\
54\end{array}$ & $\begin{array}{l}91 \\
99 \\
503\end{array}$ & $\begin{array}{l}0.07(0.05-0.10)^{* *} \\
016(0.11-0.25)^{* *} \\
\text { Reference }\end{array}$ & $\begin{array}{l}0.22(0.14-0.35)^{*} \\
0.08(0.04-0.17)^{*} \\
\text { Reference }\end{array}$ \\
\hline $\begin{array}{l}\text { CDD available while drug being offered } \\
(n=272)\end{array}$ & $\begin{array}{l}\text { Yes } \\
\text { No }\end{array}$ & $\begin{array}{l}259 \\
4\end{array}$ & $\begin{array}{l}5 \\
4\end{array}$ & $\begin{array}{l}51.80(10.01-268.19)^{* *} \\
\text { Reference }\end{array}$ & - \\
\hline
\end{tabular}

Notes: $* * P \leq 0.25$ on univariate analysis. Reference $=$ comparison group. $* P<0.05$ on multivariate analysis.

Abbreviations: COR, Crude odd ratio; AOR, Adjusted odd ratio.

On the other hand, our study indicated that the treatment coverage those aged5-10 years was $27.8 \%$, a little bit higher than the coverage within those aged $11-14$ years (27\%). The possible reason for this could be older children staying outside the home to keep cattle, which may have resulted in them missing out on the drugs. On the contrary, a study conducted in another part of Ethiopia showed that children aged $>10$ years had a higher chance of obtaining drugs. ${ }^{19}$
In this study, children who were informed on the location and time of MDA had a higher chance of drug uptake than those informed only of the time the drug was planned to be delivered. It is obvious that those participants who got information on the place and time of deworming would be able to access the drugs effectively and efficiently. A study conducted in Bangladesh supports this finding, where lack of adequate information was found to 
be a barrier to the utilization and coverage of MDA for STHs. $^{21}$

The findings of the current study demonstrate that the chance of drug uptake was higher among individuals who knew the purpose of MDA than those who did. A possible reason for this is communities that know why drugs are delivered would have more opportunity to accept and take the drugs. In line with this, previous research has shown showed that community knowledge and perceptions about the disease influenced the uptake of MDA. ${ }^{24,25}$

It is known that accessibility in terms of remoteness to reach drug-distribution points can affect uptake of drugs. ${ }^{11}$ In agreement with this, our study showed that individuals who needed to travel long distances to drug-distribution points were less likely to take drugs than those able to reach drug-distribution sites within 30 minutes.

Some limitations in this study should be taken into consideration. First, recall bias may have been a source of error if participants did not remember whether they had taken the drug or not. Second, cross-sectional studies have limitations in identifying cause-effect relationships.

\section{Conclusion}

Achieving effective and equitable MDA coverage is facing serious challenges in the hard-to-reach setting of southern Ethiopia. The findings of this study showed that the MDA coverage for STHs was much lower than the WHO's recommendation. In addition, the survey coverage was lower than the reported administrative drug coverage. School enrollment, accessibility, information, awareness, and mobilization were important risk factor of inequitable MDA coverage. Social mobilization should be scaled up to create awareness and inform the community ahead of MDA rollout. Further, exclusive school-based deworming in settings with low school enrollment needs a modified strategy to reach those in need of PC, and challenges related to implementation of MDA need further investigation.

\section{Acknowledgments}

The authors would like to sincerely thank the secretariat of the African Research Network for Neglected Tropical Diseases (ARNTD), study participants, data collectors, and administrative officials, without whom this study would not have been possible.

\section{Author Contributions}

MA wrote the original draft and was also involved in the study's conception. All authors made significant contributions to the work reported, whether in study design, execution, acquisition of data, analysis, interpretation, or all these areas, revising or critically reviewing the article, gave final approval to the version to be published, have agreed on the journal to which the article has been submitted, and agree to be accountable for all aspects of the work.

\section{Funding}

This publication was supported by a grant from the African Research Network for Neglected Tropical Diseases (ARNTD) through the US Agency for International Development (USAID), UK Aid Direct, and the Coalition for Operational Research on Neglected Tropical Diseases (COR-NTD). The contents are solely the responsibility of the authors, and do not necessarily represent the views of the ARNTD, COR-NTDs, UK Aid Direct, or USAID.

\section{Disclosure}

The authors report no conflicts of interest in this work.

\section{References}

1. World Health Organization. Uniting to combat NTDs; 2021. Available from: https://unitingtocombatntds.org/reports/5th-report/soiltransmitted-helminths-progress. Acsessed January 23, 2021.

2. World Health Organization. Soil-transmitted helminthiases: eliminating as public health problem soil-transmitted helminthiases in children: progress report 2001-2010 and strategic plan 2011-2020; 2021. Available from: https://apps.who.int/iris/bitstream/handle/10665/ 44804/9789241503129_eng.pdf. Accessed June 23, 2021.

3. World Health Organization. Guideline: Preventive Chemotherapy to Control Soil-Transmitted Helminth Infections in At-Risk Population Groups. World Health Organization; 2017.

4. Ali J, Polland A, Adlerstein D, et al. Deworming school children in Ethiopia: the importance of a comprehensive approach. Open J Trop Med. 2019;3(1):001-6. doi:10.17352/ojtm.000008

5. Asfaw MA, Wegayehu T, Gezmu T, Bekele A, Hailemariam Z, Gebre T. Determinants of soil-transmitted helminth infections among pre-schoolaged children in Gamo Gofa zone, Southern Ethiopia: a case-control study. PLoS One. 2020;15(12):e0243836. doi:10.1371/journal.pone. 0243836

6. World Health Organization. Summary of global update on preventive chemotherapy implementation in 2015. Wkly Epidemiol Rec. 2016;91 (39):441-460.

7. World Health Organization. Preventive chemotherapy in human helminthiasis. Coordinated use of anthelminthic drugs in control interventions: a manual for health professionals and programme managers. World Health Organization; 2006. Available from: https://www.cabdir ect.org/cabdirect/abstract/20073104734. Accessed June 23, 2021.

8. Pabalan N, Singian E, Tabangay L, Jarjanazi H, Boivin MJ, Ezeamama AE. Soil-transmitted helminth infection, loss of education and cognitive impairment in school-aged children: a systematic review and meta-analysis. PLoS Negl Trop Dis. 2018;12(1):e0005523. doi:10.1371/journal.pntd.0005523

9. World Health Organization. Schistosomiasis and soil-transmitted helminthiases: numbers of people treated in 2017. Wkly Epidemiol Rec. 2018;93(50):681-692. 
10. World Health Organization. Ending the neglect to attain the sustainable development goals: a road map for neglected tropical diseases 2021-2030. World Health Organization; 2020. Available from: https:/www.who.int/neglected_diseases/Ending-the-neglect-to-attainthe-SDGs-NTD-Roadmap.pdf?ua=1. Accessed June 23, 2021.

11. World Health Organization. Towards Universal Coverage for Preventive Chemotherapy for Neglected Tropical Diseases: Guidance for Assessing "Who is Being Left Behind and Why": Working Draft for Further Piloting During 2018-2019. World Health Organization; 2017.

12. Assembly G. United Nations: transforming our world: the 2030 agenda for sustainable development. Tech. Rep. 1; 2015. Available from: https://www.icnl.org/resources/library/transforming-our-worldthe-2030-agenda-for-sustainable-development. Accessed June 23, 2021.

13. World Health Organization. Universal health coverage: WHO key facts. World Health Organization; 2019. Available from: https://www who.int/news-room/fact-sheets/detail/universal-health-coverage -(uhc). Accessed January 23, 2021.

14. Federal Democratic Republic of Ethiopia Ministry of Health. Second edition of Ethiopia National Master Plan for neglected tropical diseases. Addis Ababa, Ethiopia; 2016. Available from: https://www afro.who.int/publications/second-edition-national-neglected-tropicaldiseases-master-plan-ethiopia-2016. Accessed June 23, 2021.

15. Federal Democratic Republic of Ethiopia Ministry of Health. Unpublished report of preventive chemotherapy distribution. Addis Ababa, Ethiopia. 2018.

16. Montresor A, Crompton DW, Gyorkos TW, Savioli L. Helminth Control in School-Age Children: A Guide for Managers of Control Programmes. World Health Organization; 2002.

17. Ethiopia. Office of the Population, Housing Census Commission. Summary and Statistical Report of the 2007 Population and Housing Census: Population Size by Age and Sex. Federal Democratic Republic of Ethiopia, Population Census Commission; 2008 .
18. Freeman MC, Akogun O, Belizario JV, et al. Challenges and opportunities for control and elimination of soil-transmitted helminth infection beyond 2020. PLoS Negl Trop Dis. 2019;13(4):e0007201. doi:10.1371/journal.pntd.0007201

19. Asfaw MA, Zerdo Z, Churko C, et al. Preventive chemotherapy coverage against soil-transmitted helminth infection among school age children: implications from coverage validation survey in Ethiopia, 2019. PLoS One. 2020;15(6):e0235281. doi:10.1371/journal.pone. 0235281

20. Worrell C, Mathieu E. Drug coverage surveys for neglected tropical diseases: 10 years of field experience. Am J Trop Med Hyg. 2012;87 (2):216-222. doi:10.4269/ajtmh.2012.12-0167

21. Nath TC, Padmawati RS, Murhandarwati EH. Barriers and gaps in utilization and coverage of mass drug administration program against soil-transmitted helminth infection in Bangladesh: an implementation research. J Infect Public Health. 2019;12(2):205-212. doi:10.1016/j. jiph.2018.10.002

22. Cohn DA, Kelly MP, Bhandari K, et al. Gender equity in mass drug administration for neglected tropical diseases: data from 16 countries. Int Health. 2019;11(5):370-378. doi:10.1093/inthealth/ihz012

23. Ethiopia. Coverage validation survey; 2015. Available from: https:// files.givewell.org/files/DWDA\%202009/DtWI/Deworm_the_World_ and_SCI_Ethiopia_coverage_survey.pdf. Accessed January 23, 2021.

24. Benjamin-Chung J, Nazneen A, Halder AK, et al. The interaction of deworming, improved sanitation, and household flooring with soil-transmitted helminth infection in rural Bangladesh. PLoS Negl Trop Dis. 2015;9(12):e0004256. doi:10.1371/journal.pntd.0004256

25. Dembélé M, Bamani S, Dembélé R, et al. Implementing preventive chemotherapy through an integrated national neglected tropical disease control program in Mali. PLoS Negl Trop Dis. 2012;6(3):e1574. doi:10.1371/journal.pntd.0001574
Pediatric Health, Medicine and Therapeutics

\section{Publish your work in this journal}

Pediatric Health, Medicine and Therapeutics is an international, peerreviewed, open access journal publishing original research, reports, editorials, reviews and commentaries. All aspects of health maintenance, preventative measures and disease treatment interventions are addressed within the journal. Practitioners from all disciplines are

\section{Dovepress}

invited to submit their work as well as healthcare researchers and patient support groups. The manuscript management system is completely online and includes a very quick and fair peer-review system. Visit http://www.dovepress.com/testimonials.php to read real quotes from published authors. 